\title{
Surgical outcomes of patients after treatment of ruptured anterior communicating artery aneurysms: "real- world" evidence from southern Thailand
}

\author{
Kanisorn Sungkaro, Thara Tunthanathip, Chin Taweesomboonyat and Anukoon Kaewborisutsakul ${ }^{*}$ (D)
}

\begin{abstract}
Background: Anterior communicating artery (AComA) aneurysm rupture is the most common cause of subarachnoid hemorrhage worldwide. In this study, we aimed to determine the factors associated with a poor clinical outcome in patients with ruptured AComA aneurysms undergoing microsurgical clipping.

Methods: We retrospectively reviewed the clinical and radiologic features as well as clinical outcomes of 150 consecutive patients with ruptured AComA aneurysm who underwent surgical clipping during the 11-year study period. Logistic regression analysis was performed to identify independent factors associated with unfavorable clinical outcomes (defined as a modified Rankin scale score of 3-6).

Results: The study included 83 male and 67 female patients, with a mean age of $51.3 \pm 11.5$ years. At admission, most of the patients had good neurological status, including 97 (64.7\%) patients with a Hunt and Hess grade of 1 or 2 and $109(72.6 \%)$ patients with a World Federation of Neurosurgical Societies grade of 1 or 2 . Unfavorable outcomes at 6 months were observed in 23 (22.0\%) patients, and the 6-month mortality rate was 8.0\%. Multivariate analysis showed that preoperative intraventricular hemorrhage (odds ratio [OR], 19.66; 95\% confidence interval [Cl], 5.10-75.80; $P<0.001)$, A1 hypoplasia $(\mathrm{OR}, 8.90 ; 95 \% \mathrm{Cl}, 2.82-28.04 ; P<0.001)$, and postoperative cerebral infarction $(\mathrm{OR}, 3.21 ; 95 \% \mathrm{Cl}, 1.16-8.88 ; P=0.025)$ were strong independent risk factors for unfavorable outcomes.

Conclusions: Proper management of preoperative intraventricular hemorrhage, A1 hypoplasia, and intensive care for postoperative brain infarction are warranted for improved surgical outcomes in patients with ruptured AComA aneurysm undergoing surgical clipping.
\end{abstract}

Keywords: Anterior cerebral artery, Aneurysm clipping, Low- to middle-income countries, Neurosurgery, Subarachnoid hemorrhage

\footnotetext{
*Correspondence: anukoonkaew@gmail.com

Neurological Surgery Unit, Department of Surgery, Faculty of Medicine, Prince of Songkla University, 15 Karnjanavanit Street, Kho Hong, Hat Yai District, Songkhla 90110, Thailand
} 


\section{Background}

The anterior communicating artery (AComA) is the most common location for intracranial aneurysms [1-4]. In recent years, ruptures of AComA aneurysms have been treated using endovascular treatment techniques. Nevertheless, microsurgical clipping remains the mainstay of treatment for aneurysms in this area because ruptures recur at a low rate and few subsequent treatments are needed following clipping [5].

According to recent studies, the postsurgical mortality rate for ruptured AComA aneurysms has dramatically decreased. However, morbidity rates are still high $[6,7]$, primarily due to the complexity and anatomical variations of blood vessels at the surgical site. Advanced surgical strategies, such as the skull-base technique, revascularization, or a combination of these along with endovascular treatments, might enable us to overcome these complexities [8]. Unfortunately, those treatments cannot always be performed, particularly in low- to middle-income countries, because they require sophisticated medical resources.

Since 1984, Songklanagarind Hospital, a tertiary-care hospital in southern Thailand, has treated patients with intracranial aneurysms who have been referred from hospitals in 14 provinces [4]. In the majority of the AComA surgeries performed at this hospital, pterional craniotomy is performed with simple direct clipping techniques. Therefore, the procedures described in this report represent the surgical management in most cases.

The aim of this study was to evaluate the clinical outcomes of patients with ruptured AComA aneurysms who underwent microsurgical clipping and the prognostic factors related to poor outcomes at our institute.

\section{Methods}

\section{Patient population}

This retrospective study focused on consecutive cases between January 2007 and December 2017 identified from the neurosurgical databases at our institution. The institutional ethics committee approved the protocol for this study.

We included data from all patients aged $\geq 15$ years with a ruptured AComA aneurysm who underwent microsurgical clipping. Patients with incomplete preoperative vascular imaging data and unavailable medical records were excluded, as were patients with fusiform aneurysms and vascular malformations.

\section{Data collection}

Patient characteristics, such as age, sex, presence of underlying disease, smoking, Hunt and Hess grade, and World Federation of Neurosurgical Societies (WFNS) grade at admission, were documented from the database.
The patient's preoperative status was determined using the modified Rankin scale (mRS) [9].

Preoperative imaging was reviewed by two of the authors (KS and AK). The modified Fisher scale [10] was used to classify the extent of intracranial bleeding. Vascular and aneurysmal structures were evaluated using computed tomography angiography or digital subtraction angiography, or both, depending on available data. We identified the origin and size (dome and neck width) of each aneurysm. The aneurysm dome projection was oriented in the sagittal plane, from which it could be projected predominantly into the superior, anterior, inferior, or posterior direction, according to the study by Yasargil [11].

Variations in the structure of the anterior cerebral artery (ACA), such as hypoplasia of the A1 segment, fenestrated AComA, and accessory (triplet) A2 segment, were reviewed. A1 segment hypoplasia was considered present when the A 1 width on one side was $<50 \%$ of that on the contralateral side [12].

The operative complications were reviewed, and intraoperative aneurysm ruptures were documented based on the medical records. Postoperative cerebral infarction was determined to have occurred if follow-up computed tomography showed a new area of hypoattenuation [13]. Postoperative neurological deterioration was defined as a postoperative Glasgow Coma Scale score that was $\geq 2$ points lower than the preoperative Glasgow Coma Scale score and persisted for $>24 \mathrm{~h}$ [14]. Symptomatic vasospasm was defined as a neurological deficit that reflected the function of the vascular territory for which computed tomography did not demonstrate new infarction.

The primary outcome was mortality rate during hospitalization. The secondary outcomes were neurological outcome at 6 months after the onset of aneurysmatic subarachnoid hemorrhage (aSAH), which was determined using the mRS, and factors associated with neurological outcome. Favorable and unfavorable outcomes were represented by mRS scores of $0-2$ and 3-6, respectively.

\section{Statistical analysis}

The patients characteristics and neurological outcomes were calculated as proportions for categorical and as means and standard deviations for continuous data. We performed analysis of variance to identify the prognostic factors of the 6-month neurological outcome using the mRS scores as binary variables (favorable vs. unfavorable outcome). Variables with a $P$ value of $<0.1$ in the univariate analysis were included in the multivariate logistic regression model. The model was selected using the backward stepwise (likelihood ratio) method. Prognostic factors with a $P$ value of $\leq 0.05$ were considered to indicate statistical significance. 


\section{Results}

\section{Patients and aneurysm characteristics}

We performed microsurgical clipping in 420 patients with ruptured intracranial aneurysms, of which 150 (35.7\%) had ruptured AComA aneurysms. The patients were predominantly male (83 men and 67 women) and with a mean age of 51.33 years (standard deviation, 11.49 years). Hypertension was the most common comorbidity $(n=45,30.0 \%)$, followed by diabetes mellitus $(n=13,8.7 \%)$. Most of the patients $(n=107,71.3 \%)$ presented with a sudden headache, and most patients had excellent admission neurological status with a Hunt and Hess grade of 1 or $2(n=97,64.7 \%)$ and a WFNS grade of 1 or 2 ( $n=109,72.6 \%)$. The patients' characteristics are summarized in Table 1 .

Radiographic findings included isolated thin or thick aneurysmatic SAH (modified Fisher scale score, 1 and 3) in $68(45.3 \%)$ patients. In the remaining patients $(n=82$, $54.7 \%$ ), some degree of intraventricular hemorrhage was evident. Intracerebral hemorrhage mainly within the gyrus rectus was found in 47 (31.3\%) patients (Table 2).

Digital subtraction angiography was performed for 146 patients, and the remaining 4 patients were evaluated using computed tomography angiography for preoperative planning. Angiography revealed that the AComA aneurysms primarily originated from the left A1-A2 junction (95 patients; 63.3\%) and less often from the right A1-A2 junction (47 patients; 31.3\%), and true AComA aneurysms were found only in 8 (5.3\%) patients. The mean width of the aneurysm neck was $2.96 \pm 1.16$ $\mathrm{mm}$, the mean dome width was $5.47 \pm 2.54 \mathrm{~mm}$, and the mean dome-to-neck ratio was $2.00 \pm 0.98$. The aneurysm dome was projected in the anterior direction in $70(46.7 \%)$ patients, in the superior direction in 54 (36.0\%), in the inferior direction in 21 (14.0\%), and in the posterior direction in 5 (3.3\%). Twelve (8.0\%) patients had multiple other aneurysms, none of which showed any evidence of rupture during radiographic examination (Table 2).

Variations in the structure of the ACA were detected in $85(56.7 \%)$ patients. A1 segment hypoplasia was the most common normal variation $(n=81,54.0 \%)$. In these patients, A1 segment hypoplasia was more common on the right side, and most of the aneurysms originated from the side without hypoplasia. Other variations were fenestrated AComA $(n=5,3.3 \%)$ and triplicated A2 segment $(n=2,1.3 \%)$ (Table 2$)$.

\section{Surgery and complications}

At our institution, the operation was performed as soon as possible after onset of symptoms of aneurysmatic SAH. Most of the patients $(n=101 ; 67.3 \%)$ underwent surgery within $72 \mathrm{~h}$ after onset. Delay was associated with delay in referral and hemodynamic instability.
Table 1 Baseline patient characteristics before aneurysm clipping $(n=150)$

\begin{tabular}{|c|c|}
\hline Variable & $n(\%)$ \\
\hline \multicolumn{2}{|l|}{ Sex } \\
\hline Male & $83(55.3)$ \\
\hline Female & $67(44.7)$ \\
\hline Mean age \pm SD (years) & $51.3 \pm 11.5$ \\
\hline \multicolumn{2}{|l|}{ Age } \\
\hline$<60$ & $115(76.7)$ \\
\hline$\geq 60$ & $35(23.3)$ \\
\hline \multicolumn{2}{|l|}{ Underlying disease(s) } \\
\hline Hypertension & $45(30.0)$ \\
\hline Dyslipidemia & $13(8.7)$ \\
\hline Diabetes & $4(2.7)$ \\
\hline Coagulopathy & $4(2.7)$ \\
\hline Smoking & $21(14.0)$ \\
\hline \multicolumn{2}{|l|}{ Clinical presentation(s) } \\
\hline Headache & $107(71.3)$ \\
\hline Alteration of consciousness & $81(54.0)$ \\
\hline Vomit & $60(40.0)$ \\
\hline Seizure & $27(18.0)$ \\
\hline Hemiparesis & $14(9.3)$ \\
\hline \multicolumn{2}{|l|}{ Hunt and Hess grade } \\
\hline 1 & $8(5.3)$ \\
\hline 2 & $97(64.7)$ \\
\hline 3 & $6(4.0)$ \\
\hline 4 & $26(17.3)$ \\
\hline 5 & $13(8.7)$ \\
\hline \multicolumn{2}{|l|}{ WFNS grade } \\
\hline 1 & $89(59.3)$ \\
\hline 2 & $20(13.3)$ \\
\hline 3 & $1(0.7)$ \\
\hline 4 & $24(16.0)$ \\
\hline 5 & $16(10.7)$ \\
\hline Deterioration before surgery & $21(14.0)$ \\
\hline
\end{tabular}

SD, standard deviation; WFNS, World Federation Neurological Society

Twenty-one (14\%) patients exhibited preoperative neurological deterioration, which was suspected to result from aneurysmal rebleeding.

The mean operative time was $339 \pm 68 \mathrm{~min}$, and the mean estimated blood loss was $632 \pm 314 \mathrm{~mL}$. Intraoperative aneurysmal rupture was observed in 22 (14.7\%) patients. Surgical obliteration of the aneurysmal neck was recorded as completed obliteration ( $n=146,97.3 \%)$, and incomplete obliteration was achieved with muscle wrapping $(n=1,0.7 \%)$. Data on obliteration was unavailable for $3(2 \%)$ patients (Table 3$)$. 
Table 2 Preoperative imaging of anterior communicating artery aneurysm and significant radiographic finding $(n=150)$

\begin{tabular}{|c|c|}
\hline Variable & $n(\%)$ \\
\hline \multicolumn{2}{|l|}{ Imaging modality $^{a}$} \\
\hline CTA & $4(2.7)$ \\
\hline DSA & $134(89.3)$ \\
\hline Both CTA and DSA & $12(8.0)$ \\
\hline \multicolumn{2}{|c|}{ Mean aneurysm size \pm SD $(\mathrm{mm})$} \\
\hline Dome size & $5.47 \pm 2.54$ \\
\hline Neck size & $2.96 \pm 1.16$ \\
\hline DN ratio & $2.00 \pm 0.98$ \\
\hline \multicolumn{2}{|l|}{ Origin of aneurysm } \\
\hline Right A1-A2 & $47(31.3)$ \\
\hline Left A1-A2 & $95(63.3)$ \\
\hline ACom & $8(5.3)$ \\
\hline \multicolumn{2}{|c|}{ Aneurysm dome projection in sagittal plane } \\
\hline Superior & $54(36.0)$ \\
\hline Anterior & $70(46.7)$ \\
\hline Posterior & $5(3.3)$ \\
\hline Inferior & $21(14.0)$ \\
\hline Multiple aneurysms & $12(8.0)$ \\
\hline \multicolumn{2}{|l|}{ Anatomical variations } \\
\hline A1 hypoplasia & $81(54.0)$ \\
\hline Fenestrated ACom & $5(3.3)$ \\
\hline Triplicate A2 & $2(1.3)$ \\
\hline \multicolumn{2}{|l|}{ Angiographic vasospasm } \\
\hline Diffused & $20(13.3)$ \\
\hline Local & $50(33.3)$ \\
\hline \multicolumn{2}{|l|}{ Modified Fisher grade } \\
\hline । & $39(26.0)$ \\
\hline$\|$ & $26(17.3)$ \\
\hline III & $29(19.3)$ \\
\hline IV & $56(37.3)$ \\
\hline Intracerebral hemorrhage & $47(31.3)$ \\
\hline Intraventricular hemorrhage & $82(54.7)$ \\
\hline Hydrocephalus & 19 (12.7) \\
\hline
\end{tabular}

${ }^{a}$ Cranial computed tomography scans were included in all cases $\mathrm{ACom}$, anterior communicating artery; $\mathrm{A} 1, \mathrm{~A} 1$ segment of anterior cerebral artery; A2, A2 segment of anterior cerebral artery; CTA, computed tomography angiography; DN, dome-to-neck; DSA, digital subtraction angiography; SD, standard deviation

Postoperative complications were divided into operation-related and systemic events. Postoperative cerebral infarction was seen in 55 (36.7\%) patients, neurological deterioration in 38 (25.3\%), and symptomatic vasospasm in 33 (22.0\%). Eight (5.3\%) patients developed seizures after surgery, but these could be controlled with a single antiepileptic drug. Postoperative infection was found in $38(25.3 \%)$ patients, which
Table 3 Microsurgical clipping for anterior cerebral artery aneurysm and postoperative complications $(n=150)$

\begin{tabular}{|c|c|}
\hline Variable & $n(\%)$ \\
\hline \multicolumn{2}{|l|}{ Time from onset to surgery (hours) } \\
\hline$<72$ & $101(67.3)$ \\
\hline$\geq 72$ & $49(32.7)$ \\
\hline \multicolumn{2}{|l|}{ Surgical side } \\
\hline Right & $51(34.0)$ \\
\hline Left & $99(66.0)$ \\
\hline \multicolumn{2}{|l|}{ Aneurysm obliteration $^{a}$} \\
\hline Complete & $146(97.3)$ \\
\hline Incomplete & $1(0.7)$ \\
\hline NA & $3(2.0)$ \\
\hline Interoperative rupture & $22(14.7)$ \\
\hline \multicolumn{2}{|l|}{ Number clip(s) } \\
\hline 1 & $106(70.6)$ \\
\hline 2 & $39(26.0)$ \\
\hline 3 & $5(3.3)$ \\
\hline Mean operation time \pm SD (min) & $339.2 \pm 68.2$ \\
\hline Mean estimate blood loss $\pm \mathrm{SD}(\mathrm{mL})$ & $632.4 \pm 314.6$ \\
\hline \multicolumn{2}{|l|}{ Intracranial complications } \\
\hline Cerebral infarction & $55(36.7)$ \\
\hline Neurological worsening & $38(25.3)$ \\
\hline Symptomatic vasospasm & $33(22.0)$ \\
\hline Hydrocephalus & $9(6.0)$ \\
\hline Seizure & $8(5.3)$ \\
\hline Intracerebral hemorrhage & $4(2.7)$ \\
\hline \multicolumn{2}{|l|}{ Systemic complications } \\
\hline Acute DVT & $2(1.3)$ \\
\hline Acute PE & $1(0.7)$ \\
\hline Infectious complications & $38(25.3)$ \\
\hline Pneumonia & $17(11.3)$ \\
\hline Urinary tract infection & $8(5.3)$ \\
\hline Meningitis & $6(4.0)$ \\
\hline Wound infection & $1(0.7)$ \\
\hline Mean LOS \pm SD (days) & $22.8 \pm 38.7$ (range $1-315$ days) \\
\hline
\end{tabular}

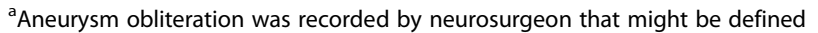
by direct observation or using intravenous indocyanine green injection DVT, deep vein thrombosis of leg; LOS, length of hospital stays; NA, not available; PE, pulmonary embolism; SD, standard deviation; UTI, urinary tract infection

manifested as pneumonia in $17(11.3 \%)$ patients. Venous thromboembolism was found in $3(2 \%)$ patients.

\section{Neurological outcomes}

Seven $(4.7 \%)$ patients died related to intracranial causes during hospitalization. The other patients were monitored at the outpatient clinic during the rehabilitation 
period. At postoperative 6 months, 9 (6\%) patients were lost to follow-up, and 108 (71.9\%) patients achieved favorable outcomes with $\mathrm{mRS}$ scores of $0-2$. There were five out-of-hospital deaths, including three patients who died due to acute coronary disease, one patient died due to putaminal hemorrhage and one patient in whom the cause of death could not be identified. Therefore, there were a total of $12(8.0 \%)$ deaths in the study period (Table 4).

\section{Risk factors for unfavorable outcomes at 6 months}

Thirty-three patients (22\%) had an unfavorable outcome at postoperative 6 months. Univariate analysis showed that age $\geq 60$ years, the presence of hypertension, alteration of consciousness during aneurysmatic SAH onset, poor Hunt and Hess and WFNS grades (3-5) on admission, dome-to-neck ratio $<2$, A1 segment hypoplasia, preoperative intraventricular hemorrhage (IVH), postoperative cerebral infarction, and infectious complications were associated with unfavorable outcomes.

Moreover, multivariate logistic regression analysis revealed that the prognostic factors significantly associated with unfavorable outcomes were preoperative IVH (odds ratio, 19.7; 95\% confidence interval, 5.1-75.8; $P<0.001$ ), A1 segment hypoplasia (odds ratio, 8.9; 95\% confidence interval, 2.8-28.0; $P<0.001$ ), and postoperative cerebral infarction (odds ratio, 3.2; 95\% confidence interval, $1.2-$ 8.9; $P=0.025$; Table 5).

\section{Discussion}

In this study, we evaluated the prognostic factors for unfavorable clinical outcomes after surgical clipping of ruptured AComA aneurysms. The clinical outcomes at postoperative 6 months were poor in $22 \%$ of the patients, a rate comparable with those of previous studies (range, 12.78-32.80\%) [13, 15-17]. Preoperative IVH, A1 segment hypoplasia, and postoperative cerebral infarction

Table 4 Neurological outcome in ruptured anterior communicating artery aneurysm $(n=150)$

\begin{tabular}{ll}
\hline Variable & $\boldsymbol{n}(\%)$ \\
\hline In-hospital mortality & $7(4.7)$ \\
mRS 6 months & \\
0 & $2(1.3)$ \\
1 & $29(19.3)$ \\
2 & $77(51.4)$ \\
3 & $10(6.7)$ \\
4 & $5(3.3)$ \\
5 & $6(4.0)$ \\
6 (deaths) & $12(8.0)$ \\
NA & $9(6.0)$ \\
\hline
\end{tabular}

mRS, modified Rankin scale; NA, not available were significant prognostic factors for unfavorable outcomes at 6 months.

IVH frequently occurs with spontaneous SAH. In the present study, more than $50 \%$ of the patients were had IVH and 19 (12.7\%) patients had hydrocephalus at the onset of SAH. Rosen et al. found that $45 \%$ of patients had IVH at the onset of SAH [18]. The clinical condition of these patients tended to be poorer than that of patients without IVH. These patients tended to have more premorbid medical conditions. Furthermore, they were more likely to have thick SAH, develop vasospasm and hydrocephalus, and have poorer outcomes. Smith et al. [19] identified that the Fisher grade was correlated with symptomatic vasospasm in $50 \%$ of the patients in their study. More than $50 \%$ of the patients with large IVHs were admitted to hospitals with poor clinical grades, and the overall mortality rate was $64 \%$ [20]. IVH is a definitive independent risk factor for death, disability, and chronic hydrocephalus after SAH [21, 22].

Patients with IVH with concomitant acute hydrocephalus have markedly increased intracranial pressure and require ventricular drainage [23]. Intraventricular thrombolysis with recombinant tissue plasminogen activator, performed via ventriculostomy tube, seems to benefit patients with spontaneous IVH as it helps to normalize intracranial pressure, reduce ventricular obstruction, improve neurological function, and reduce mortality $[24,25]$. The CLEAR III trial, however, did not show improved functional outcome, but it confirmed a reduction in the mortality rate [26]. Thus, IVH caused by rupture of an intracranial aneurysm is of great concern, and appropriate treatment can improve the functional outcome. Proper management of aneurysmal IVH should be clarified in future clinical trials.

A1 hypoplasia of the ACA was the most frequent anatomic variation in our study. Previous studies had documented a prevalence of A1 segment hypoplasia ranging from $24-85 \%$ in patients with AComA aneurysms [2730]. In our study, 81 (54.0\%) patients had A1 segment hypoplasia, and this is consistent with those in previous studies. The relationship between aneurysm formation and A1 segment hypoplasia may be attributed to asymmetric local inflow with chronic hemodynamic stress on the wall of the junction between the A1 and A2 segments. Moreover, the possible role of A1 segment hypoplasia in the treatment success of AComA aneurysm has also been debated. Yang et al. [30] found that A1 segment hypoplasia was related to unfavorable clinical outcomes. However, Jabbarli et al. [31], who investigated patients undergoing surgical clipping, found that A1 segment hypoplasia had no independent predictive value for functional outcome. In our study, A1 segment hypoplasia was found to be a strong independent risk factor for an unfavorable clinical outcome $(P<0.001)$. The 
Table 5 Factor associated unfavorable outcome (mRS 3-6) at postoperative 6 months in patients with ruptured anterior communicating artery aneurysm by binary logistic regression analysis $(n=141)$

\begin{tabular}{|c|c|c|c|c|}
\hline \multirow[b]{2}{*}{ Factor } & \multicolumn{2}{|l|}{ Univariable analysis } & \multicolumn{2}{|c|}{ Multivariable analysis $^{a}$} \\
\hline & Odds ratio $(95 \% \mathrm{Cl})$ & $P$ value & Odds ratio $(95 \% \mathrm{Cl})$ & $P$ value \\
\hline Female & $1.49(0.68-3.25)$ & 0.320 & & \\
\hline Age $\geq 60$ & $4.17(1.78-9.77)$ & 0.001 & & \\
\hline Hypertension & $3.35(1.49-7.55)$ & 0.004 & & \\
\hline \multicolumn{5}{|l|}{ Presenting symptom } \\
\hline Headache & $0.67(0.30-1.54)$ & 0.360 & & \\
\hline Vomiting & $1.31(0.60-2.88)$ & 0.500 & & \\
\hline Alteration of consciousness & $4.15(1.66-10.38)$ & 0.002 & & \\
\hline Seizure & $0.54(0.17-1.70)$ & 0.290 & & \\
\hline Hemiparesis & $2.58(0.76-8.74)$ & 0.130 & & \\
\hline Deterioration prior surgery & $2.56(0.95-6.94)$ & 0.065 & & \\
\hline $\mathrm{HH}$ grades $3-5$ & $2.38(1.06-5.35)$ & 0.036 & & \\
\hline WFNS grades 3-5 & $2.45(1.08-5.57)$ & 0.033 & & \\
\hline \multicolumn{5}{|l|}{ Aneurysm characteristics } \\
\hline Neck width $\geq 4 \mathrm{~mm}$ & $0.48(0.15-1.51)$ & 0.210 & & \\
\hline DN ratio $\geq 2$ & $0.43(0.20-0.96)$ & 0.039 & & \\
\hline A1 hypoplasia & $7.00(2.51-19.50)$ & $<0.001$ & $8.90(2.82-28.04)$ & $<0.001$ \\
\hline Multiple aneurysm & $3.04(0.86-10.68)$ & 0.084 & & \\
\hline Pre ICH & $1.03(0.44-2.42)$ & 0.940 & & \\
\hline Pre HCP & $2.97(0.53-16.49)$ & 0.220 & & \\
\hline Pre IVH & $15.71(4.51-54.75)$ & $<0.001$ & $19.66(5.10-75.80)$ & $<0.001$ \\
\hline Delayed surgery & $1.14(0.50-2.61)$ & 0.760 & & \\
\hline Multiple clips ( $\geq 2$ ) & $1.71(0.75-3.90)$ & 0.201 & & \\
\hline Intraoperative rupture & $0.96(0.32-2.84)$ & 0.940 & & \\
\hline Operative time $\geq 5 \mathrm{~h}$ & $1.06(0.41-2.74)$ & 0.900 & & \\
\hline Estimated blood loss $\geq 600 \mathrm{~mL}$ & $1.39(0.61-3.13)$ & 0.430 & & \\
\hline \multicolumn{5}{|l|}{ Complications } \\
\hline Intracerebral hemorrhage & $10.30(1.03-102.67)$ & 0.047 & & \\
\hline Neurological worse & $2.28(0.99-5.23)$ & 0.053 & & \\
\hline Symptomatic vasospasm & $2.34(0.97-5.63)$ & 0.057 & & \\
\hline Cerebral infarction & $2.96(1.33-6.62)$ & 0.008 & $3.21(1.16-8.88)$ & 0.025 \\
\hline Infectious complications & $5.28(2.28-12.23)$ & $<0.001$ & & \\
\hline
\end{tabular}

${ }^{a}$ Value shows only the significant values in final model of multivariable logistic regression with backward elimination (likelihood ratio) method $\mathrm{Cl}$, confidence interval; DN, dome-to-neck; $\mathrm{HH}$, Hunt and Hess grade; mRS, modified Rankin scale; Pre ICH, preoperative intracerebral hemorrhage; Pre IVH, preoperative intraventricular hemorrhage; WFNS, World Federation Neurological Society

operative risk for patients with A1 segment hypoplasia was also higher than that in patients without this anatomic variant. From our findings, we hypothesized that unfavorable outcomes result from injury to the A1 segment of ACA or that some degree of induced vasospasm is caused by temporary parent artery clipping. Patients with A1 segment hypoplasia were more likely to have ischemia in the vicinity of the ACA or infarction because no compensatory blood could reach the distal brain. In patients without A1 segment hypoplasia, compensatory blood flow from the contralateral ACA or AComA may confer a better clinical outcome. Therefore, for patients with ruptured AComA aneurysms and A1 segment hypoplasia, we strongly recommended the use of intraoperative neurophysiologic monitoring that can enable early detection of cerebral ischemia. However, if this technology is not available, particularly in situations with limited resources, temporary clipping of the parent artery should be only minimal or altogether avoided. Unfortunately, the optimal 
time for proximal control with temporary clipping was not established in our study.

Cerebral infarction is considered a severe complication of SAH leading morbidity and mortality. The causes of postoperative cerebral infarction are diverse. However, identifying the cause is crucial for determining a preventive strategy. A strong association of higher Fisher grades and development of cerebral vasospasm has been demonstrated [32]. As mentioned previously, Smith et al. [19] found that Fisher grade was correlated with symptomatic vasospasm in $50 \%$ of their patients; however, we found that the modified Fisher grade was not a significant factor for unfavorable clinical outcomes. Unfortunately, the power of this study, statistically, was not sufficient to further evaluate the factors related to cerebral infarction.

\section{Study limitations}

Our study had several limitations. A major limitation was the possibility of retrospective bias. Many important factors, such as duration of temporary clipping of the A1 segment or details of intraoperative aneurysm rupture and its management, could not be defined. Second, this study included data from a single center, and sampling and selection for clipping or coiling may have created unavoidable bias. Third, this study spanned a large time period; therefore, changes in the experience of surgeons and intensive care treatments were unavoidable. Fourth, the sample size was too small to evaluate the direct effect of each significant prognostic factor. Therefore, a multicenter study should be established. However, our review of the literature revealed that no study has reported real-world results; therefore, the findings of this study should be of use for the treatment of these patients.

Finally, long-term follow-up after aneurysm treatment was not performed. Many studies have shown that the clinical outcome improves over time [33, 34]; thus, a short follow-up time might not reflect long-term outcomes. We evaluated patient outcomes over a 6-month period in this study because it was sufficient time to evaluate the short-term outcomes and because the number of patients lost to long-term follow-up could have invalidated our findings.

\section{Conclusions}

The majority of patients with ruptured AComA aneurysms who underwent surgical clipping at our institution achieved a favorable 6-month outcome. Factors related to poor prognosis included individual anatomic conditions (A1 segment hypoplasia), disease severity (preoperative IVH), and postoperative consequence (cerebral ischemia). Further studies are warranted to evaluate and establish proper preventive strategies for better management of such patients.

\section{Abbreviations}

ACom: Anterior communicating artery; AComA: Anterior communicating artery aneurysm; CT: Computed tomography; CTA: Computed tomography angiography; DSA: Digital subtraction angiography; aSAH: Aneurysmal

subarachnoid hemorrhage

\section{Acknowledgements}

The authors acknowledge with appreciation the medical instructors and team members from the Department of Neurosurgery, Faculty of Medicine, Prince of Songkla University, for their support in collecting patient data.

\section{Authors' contributions}

$\Pi$, $C T$, and AK performed the operations and designed the study. KS collected the patient data and evaluated images with AK. TT and AK participated in the statistical analysis. KS and AK drafted the manuscript. All authors read and approved the final manuscript.

\section{Funding}

Not applicable.

\section{Availability of data and materials}

The datasets used in the present study are available from the corresponding author on reasonable request.

\section{Declarations}

\section{Ethics approval and consent to participate}

The study protocol was approved by the ethic committee of the Faculty of Medicine, Prince of Songkla University (REC.62-350-10-4). The requirement for informed consent was waived due to the retrospective study design.

\section{Consent for publication}

Not applicable.

\section{Competing interests}

The authors declare that they have no competing interests.

Received: 10 May 2021 Accepted: 6 September 2021

Published online: 02 October 2021

\section{References}

1. Molyneux A, Kerr R, Stratton I, Sandercock P, Clarke M, Shrimpton J, et al. International Subarachnoid Aneurysm Trial (ISAT) of neurosurgical clipping versus endovascular coiling in 2143 patients with ruptured intracranial aneurysms: a randomised trial. Lancet. 2002;360(9342):1267-74. https://doi. org/10.1016/S0140-6736(02)11314-6.

2. Locksley HB. Natural history of subarachnoid hemorrhage, intracranial aneurysms and arteriovenous malformations. Based on 6368 cases in the cooperative study. J Neurosurg. 1966;25(2):219-39. https://doi.org/10.3171/ jns.1966.25.2.0219.

3. Amarttayakong P, Woraputtaporn W, Prajaney P, lamsaard S, Munkong W, Sangkhano S. Predisposition of sex and aging to ruptured intracerebral aneurysms: a retrospective study by 3DRA. Srinagarind Med J. 2018;33:4807.

4. Phuenpathom N, Ratanalert S, Tussanasunthonwong S. Experiences in intracranial aneurysm surgery in southern Thailand. Thai J Surg. 1994;15:406.

5. Molyneux AJ, Kerr RS, Birks J, Ramzi N, Yarnold J, Sneade M, et al. Risk of recurrent subarachnoid haemorrhage, death, or dependence and standardised mortality ratios after clipping or coiling of an intracranial aneurysm in the International Subarachnoid Aneurysm Trial (ISAT): longterm follow-up. Lancet Neurol. 2009;8(5):427-33. https://doi.org/10.1016/S14 74-4422(09)70080-8.

6. Molyneux AJ, Kerr RSC, Yu L-M, Clarke M, Sneade M, Yarnold JA, et al. International subarachnoid aneurysm trial (ISAT) of neurosurgical clipping versus endovascular coiling in 2143 patients with ruptured intracranial aneurysms: a randomised comparison of effects on survival, dependency, seizures, rebleeding, subgroups, and aneurysm occlusion. Lancet. 2005; 366(9488):809-17. https://doi.org/10.1016/S0140-6736(05)67214-5.

7. Abla AA, Wilson DA, Williamson RW, Nakaji P, McDougall CG, Zabramski JM, et al. The relationship between ruptured aneurysm location, subarachnoid 
hemorrhage clot thickness, and incidence of radiographic or symptomatic vasospasm in patients enrolled in a prospective randomized controlled trial. J Neurosurg. 2014;120(2):391-7. https://doi.org/10.3171/2013.10.JNS13419.

8. Ren Z, Wang S, Xu K, Mokin M, Zhao Y, Cao Y, et al. The working road map in a neurosurgical Hybrid Angio-Surgical suite------ development and practice of a neurosurgical Hybrid Angio-Surgical suite. Chin Neurosurg J. 2018;4(1):7. https://doi.org/10.1186/s41016-017-0108-1.

9. Quinn TJ, Dawson J, Walters MR, Lees KR. Reliability of the modified Rankin Scale: a systematic review. Stroke. 2009;40(10):3393-5. https://doi.org/10.11 61/STROKEAHA.109.557256.

10. Frontera JA, Claassen J, Schmidt JM, Wartenberg KE, Temes R, Connolly ES, et al. Prediction of symptomatic vasospasm after subarachnoid hemorrhage: the modified fisher scale. Neurosurgery. 2006;59(1):21-7. https://doi.org/1 0.1227/01.NEU.0000218821.34014.1B.

11. Yasargil MG. Microneurosurgery, volume II: clinical considerations, surgery of the intracranial aneurysms and results. New York: Thieme; 1984.

12. Rinaldo L, McCutcheon BA, Murphy ME, Bydon M, Rabinstein AA, Lanzino G. Relationship of A1 segment hypoplasia to anterior communicating artery aneurysm morphology and risk factors for aneurysm formation. J Neurosurg. 2017;127(1):89-95. https://doi.org/10.3171/2016.7.JNS16736.

13. Heit JJ, Ball RL, Telischak NA, Do HM, Dodd RL, Steinberg GK, et al. Patient outcomes and cerebral infarction after ruptured anterior communicating artery aneurysm treatment. Am J Neuroradiol. 2017;38(11):2119-25. https:// doi.org/10.3174/ajnr.A5355.

14. Hindman BJ, Bayman EO, Pfisterer WK, Torner JC, Todd MM, on behalf of the IHAST Investigators. No association between intraoperative hypothermia or supplemental protective drug and neurologic outcomes in patients undergoing temporary clipping during cerebral aneurysm surgery Anesthesiology. 2010;112(1):86-101. https://doi.org/10.1097/ALN.0b013e31 $81 \mathrm{c} 5 \mathrm{e} 28 \mathrm{f}$.

15. Yao P, Chen G, Zheng S, Kang D. Predictors of postoperative cerebral ischemia in patients with ruptured anterior communicating artery aneurysms. World Neurosurg. 2017;103:241-7. https://doi.org/10.1016/j. wneu.2017.04.007.

16. Suzuki M, Fujisawa H, Ishihara H, Yoneda H, Kato S, Ogawa A. Side selection of pterional approach for anterior communicating artery aneurysms surgical anatomy and strategy. Acta Neurochir (Wien). 2008;150(1):31-9. https://doi.org/10.1007/s00701-007-1466-9.

17. Proust F, Debono B, Hannequin D, Gerardin E, Clavier E, Langlois $\mathrm{O}$, et al. Treatment of anterior communicating artery aneurysms: complementary aspects of microsurgical and endovascular procedures. J Neurosurg. 2003; 99(1):3-14. https://doi.org/10.3171/jns.2003.99.1.0003.

18. Rosen DS, Macdonald RL, Huo D, Goldenberg FD, Novakovic RL, Frank Jl, et al. Intraventricular hemorrhage from ruptured aneurysm: clinical characteristics, complications, and outcomes in a large, prospective, multicenter study population. J Neurosurg. 2007;107(2):261-5. https://doi. org/10.3171/JNS-07/08/0261

19. Smith ML, Abrahams JM, Chandela S, Smith MJ, Hurst RW, Le Roux PD. Subarachnoid hemorrhage on computed tomography scanning and the development of cerebral vasospasm: the Fisher grade revisited. Surg Neurol. 2005;63(3):229-34. https://doi.org/10.1016/j.surneu.2004.06.017.

20. Mohr G, Ferguson G, Khan M, Malloy D, Watts R, Benoit B, et al. Intraventricular hemorrhage from ruptured aneurysm: retrospective analysis of 91 cases. J Neurosurg. 1983;58(4):482-7. https://doi.org/10.3171/jns.1983. 58.4.0482.

21. Dorai Z, Hynan LS, Kopitnik TA, Samson D. Factors related to hydrocephalus after aneurysmal subarachnoid hemorrhage. Neurosurgery. 2003;52(4):763-9. https://doi.org/10.1227/01.NEU.0000053222.74852.2D.

22. Macdonald RL, Karrison T. Factors associated with the development of vasospasm after planned surgical treatment of aneurysmal subarachnoid hemorrhage. J Neurosurg. 2003;99:9.

23. Hasan D, Vermeulen M, Wijdicks EFM, Hydra A, van Gijn J. Management problems in acute hydrocephalus after subarachnoid hemorrhage. Stroke. 1989;20(6):747-53. https://doi.org/10.1161/01.STR.20.6.747.

24. Findlay JM, Jacka MJ. Cohort study of intraventricular thrombolysis with recombinant tissue plasminogen activator for aneurysmal intraventricular hemorrhage. Neurosurgery. 2004;55(3):532-7. https://doi.org/10.1227/01. NEU.0000134473.98192.B1.

25. Moradiya Y, Murthy SB, Newman-Toker DE, Hanley DF, Ziai WC. Intraventricular thrombolysis in intracerebral hemorrhage requiring ventriculostomy. Stroke. 2014;45(9):2629-35. https://doi.org/10.1161/ STROKEAHA.114.006067.

26. Hanley DF, Lane K, McBee N, Ziai W, Tuhrim S, Lees KR, et al. Investigators. Thrombolytic removal of intraventricular haemorrhage in treatment of severe stroke: results of the randomised, multicentre, multiregion, placebocontrolled CLEAR III trial. Lancet. 2017;11(389):603-11.

27. Krzyzewski RM, Tomaszewska IM, Lorenc N, Kochana M, Goncerz G, KlimekPiotrowska W, et al. Variations of the anterior communicating artery complex and occurrence of anterior communicating artery aneurysm: A2 segment consideration. Folia Med Cracov. 2014;54(1):13-20.

28. Kasuya H, Shimizu T, Nakaya K, Sasahara A, Hori T, Takakura K. Angles between $A 1$ and $A 2$ segments of the anterior cerebral artery visualized by three-dimensional computed tomographic angiography and association of anterior communicating artery aneurysms. Neurosurgery. 1999;45:89-93.

29. Wilson $\mathrm{G}$, Riggs HE, Rupp C. The pathologic anatomy of ruptured cerebral aneurysms. J Neurosurg. 1954;11(2):128-34. https://doi.org/10.3171/jns.1 954.11.2.0128.

30. Yang F, Li H, Wu J, Li M, Chen X, Jiang P, et al. Relationship of A1 segment hypoplasia with the radiologic and clinical outcomes of surgical clipping of anterior communicating artery aneurysms. World Neurosurg. 2017;106:80612. https://doi.org/10.1016/j.wneu.2017.07.122.

31. Jabbarli R, Reinhard M, Roelz R, Kaier K, Weyerbrock A, Taschner C, et al. Clinical relevance of anterior cerebral artery asymmetry in aneurysmal subarachnoid hemorrhage. J Neurosurg. 2017;127(5):1070-6. https://doi. org/10.3171/2016.9.JNS161706.

32. Ko SB, Choi HA, Carpenter AM, Helbok R, Schmidt JM, Badjatia N, et al. Quantitative analysis of hemorrhage volume for predicting delayed cerebral ischemia after subarachnoid hemorrhage. Stroke. 2011;42(3):669-74. https:// doi.org/10.1161/STROKEAHA.110.600775.

33. Molyneux AJ, Birks J, Clarke A, Sneade M, Kerr RSC. The durability of endovascular coiling versus neurosurgical clipping of ruptured cerebral aneurysms: 18 year follow-up of the UK cohort of the International Subarachnoid Aneurysm Trial (ISAT). Lancet. 2015;385(9969):691-7. https:// doi.org/10.1016/S0140-6736(14)60975-2.

34. Spetzler RF, McDougall CG, Zabramski JM, Albuquerque FC, Hills NK, Russin JJ, et al. The Barrow ruptured aneurysm trial: 6-year results. J Neurosurg. 2015;123(3):609-17. https://doi.org/10.3171/2014.9.JNS141749.

\section{Ready to submit your research? Choose BMC and benefit from:}

- fast, convenient online submission

- thorough peer review by experienced researchers in your field

- rapid publication on acceptance

- support for research data, including large and complex data types

- gold Open Access which fosters wider collaboration and increased citations

- maximum visibility for your research: over $100 \mathrm{M}$ website views per year

At $\mathrm{BMC}$, research is always in progress.

Learn more biomedcentral.com/submission 